\title{
Association of Immune Status with Recurrent Anal Condylomata in Human Immunodeficiency Virus-Positive Patients
}

\author{
Ji Hyun Sung, Eun Jung Ahn, Heung-Kwon Oh, Sei Hyeog Park \\ Department of Surgery, National Medical Center, Seoul, Korea
}

Purpose: An anal condyloma is a proliferative disease of the genital epithelium caused by the human papillomavirus. This condition is most commonly seen in male homosexuals and is frequently recurrent. Some reports have suggested that immunosuppression is a risk factor for recurrence of a condyloma. Thus, we investigated the risk factors for a recurrent anal condyloma in human immunodeficiency virus (HIV)-positive patients.

Methods: We retrospectively analyzed 85 consecutive patients who were diagnosed with and underwent surgery for an anal condyloma from January 2007 to December 2011. Outcomes were analyzed based clinical and immunologic data.

Results: Recurrent anal condylomata were found in 25 patients $(29.4 \%)$. Ten cases (40.0\%) were within postoperative 3 months. At postoperative 6 months, the CD4 lymphocyte count in the recurrent group was lower than it was in the nonrecurrent group $(\mathrm{P}=0.023)$.

Conclusion: CD4-mediated immunosuppression is a risk factor for recurrent anal condylomata in HIV-positive patients.

Keywords: Condyloma accuminata; Human papillomavirus; HIV; Recurrence; Immunosuppression

\section{INTRODUCTION}

An anal condyloma is a sexually transmitted disease caused by the human papillomavirus (HPV) that generates hyperplastic changes in the mucosa and the skin of the perineum. Although it occurs regardless of gender, it most commonly affects human immunodeficiency virus (HIV)-infected homosexual men [1]. Although anal condylomata mostly appear as small lesions without pain, pruritus, and bleeding, they have a potential for malignant transformation. Because the infection is frequently asymptomatic, the primary treatment is aimed to eliminate symptomatic lesions. Therapeutic methods can be classified into nonoperative and op-

Received: August 31, 2012 - Accepted: October 26, 2012

Correspondence to: Eun Jung Ahn, M.D.

Department of Surgery, National Medical Center, 245 Eulji-ro, Jung-gu,

Seoul 100-799, Korea

Tel: +82-2-2260-7164, Fax: +82-2-2269-0750

E-mail: astroej@naver.com

(c) 2012 The Korean Society of Coloproctology

This is an open-access article distributed under the terms of the Creative Commons Attribution NonCommercial License (http://creativecommons.org/licenses/by-nc/3.0) which permits unrestricted noncommercial use, distribution, and reproduction in any medium, provided the original work is properly cited. erative treatment methods. Although reports vary depending on treatment methods and researchers, the recurrence rate is as high as 50 to $60 \%$ [2]. Severity of dysplasia, HPV subtypes, and sexual intercourse patterns have been suggested as the causes of recurrence of anal condylomata. However, cell-mediated immunity has drawn the most attention [3-7]. The prevalence and recurrent rates of anal condylomata are much higher in patients with compromised immune function compare to healthy individuals, and this has been verified by many studies [7-9].

Recently, the number of HIV-infected patients has been gradually increasing in Korea. According to the Korea Federation for AIDS Prevention, the first report of an HIV-infected patient occurred in 1985, and the total number of HIV-positive patients has rapidly increased from 1,607 in 2001 to 8,544 in 2011. The incidence rates are around ten times higher in males than in females. A confirmed 281 new cases in 2001 increased to 948 new cases in 2007, an approximately threefold increase [10]. However, only a few studies have been performed on anal condylomata domestically. In this regard, the authors of the study aimed to investigate factors associated with the postoperative recurrence of surgically-treated anal condylomata detected in HIV positive patients. 


\section{METHODS}

The subjects of this study included HIV-positive patients who had been diagnosed as having an anal condyloma and who had been surgically treated at National Medical Center from January 2007 to December 2011. We analyzed age, gender, transmission routes, sexual behavior, the presence of highly active antiretroviral therapy (HAART), combined infectious diseases, the number of CD4 and CD8 lymphocytes, and HIV RNA copy numbers by performing a retrospective medical record review.

Surgery was performed in the prone position under spinal anesthesia by a single specialized colorectal surgeon. Large-sized or pedunculated masses were resected by examining the skin around the anus and intraanal canal with the naked eye. Meanwhile, smallsized and sessile masses were removed using the electrocautery method. An anal condyloma was confirmed by performing a histopathological examination for all patients. The follow-up for recurrence of the anal condyloma was conducted at the outpatient clinic in the first postoperative week and in the first, third and sixth postoperative months. The medical records included results acquired from regularly-performed examinations, including the number of CD4 and CD8 lymphocytes and the HIV RNA copy numbers, as well as other information from the Infectious Diseases Section of the Department of Internal Medicine. Serologic results obtained one month earlier and one month later were considered valid when comparing the diagnoses, the time of surgery, and dates of outpatient treatment for an anal condyloma.

Statistical analyses were performed using IBM SPSS ver. 20 (IBM Co., Armonk, NY, USA), and clinical manifestations, including transmission routes, sexual preference, and the presence of HAART and other associated infectious diseases, were analyzed using Pearson's chi-square test. The number of CD4 and CD8 lymphocytes, and the HIV RNA copy numbers were analyzed using a Student's t-test. P-values of less than 0.05 were considered statistically significant.

\section{RESULTS}

The 85 subjects were all male. Most subjects were HIV positive patients who had contracted HIV through sexual contact (98.8\%), and about $2 / 3$ of the subjects were homosexuals (70.6\%). About $2 / 3$ of the patients contracted cytomegalovirus infection associated with condyloma, and about $1 / 3$ of the patients were confirmed with hepatitis A virus infection and syphilis (Table 1).

Recurrence was detected in 25 patients (29.4\%), and the average time to recurrence was 5.1 months (range, 1.3 to 14.2 months). The recurrence rate was highest during the first three postoperative months, with recurrence in 10 patients (40.0\%). Recurrence was confirmed in 7 patients (28.0\%) between the third and the sixth postoperative months, and in 8 patients after the first six postoperative months. Although most patients (20 patients, $80.0 \%$ ) had single recurrence, one patient (4.0\%) experienced more than
Table 1. Clinical characteristics of the patients

\begin{tabular}{|c|c|}
\hline Characteristic & Value \\
\hline Age (yr) & $34.6(19-68)$ \\
\hline \multicolumn{2}{|l|}{ Gender } \\
\hline Male & $85(100)$ \\
\hline Female & $0(0)$ \\
\hline \multicolumn{2}{|l|}{ Mode of transmission (HIV) } \\
\hline Sexual contact & $84(98.8)$ \\
\hline Transfusion & $1(1.2)$ \\
\hline \multicolumn{2}{|l|}{ Sexual behavior } \\
\hline Homosexual & $60(70.6)$ \\
\hline Heterosexual & $5(5.9)$ \\
\hline Bisexual & $4(4.7)$ \\
\hline No response & $16(18.8)$ \\
\hline \multicolumn{2}{|l|}{ HAART } \\
\hline Yes & $45(52.9)$ \\
\hline No & $40(47.1)$ \\
\hline \multicolumn{2}{|l|}{ Coinfections } \\
\hline None & $16(18.8)$ \\
\hline CMV & $23(27.1))$ \\
\hline Syphilis & $8(9.4)$ \\
\hline HAV & $2(2.4)$ \\
\hline CMV \& HAV & $22(25.9)$ \\
\hline CMV \& syphilis & $8(9.4)$ \\
\hline CMV, HAV, \& syphilis & $5(5.9)$ \\
\hline CMV, HAV, syphilis, \& HBV & $1(1.2)$ \\
\hline
\end{tabular}

Values are presented as mean (range) or number (\%).

HIV, human immunodeficiency virus; HAART, highly active antiretroviral therapy; $\mathrm{CMV}$, cytomegalovirus; HAV, hepatitis A virus; $\mathrm{HBV}$, hepatitis B virus.

Nonrecurrent $\square$ Recurrent

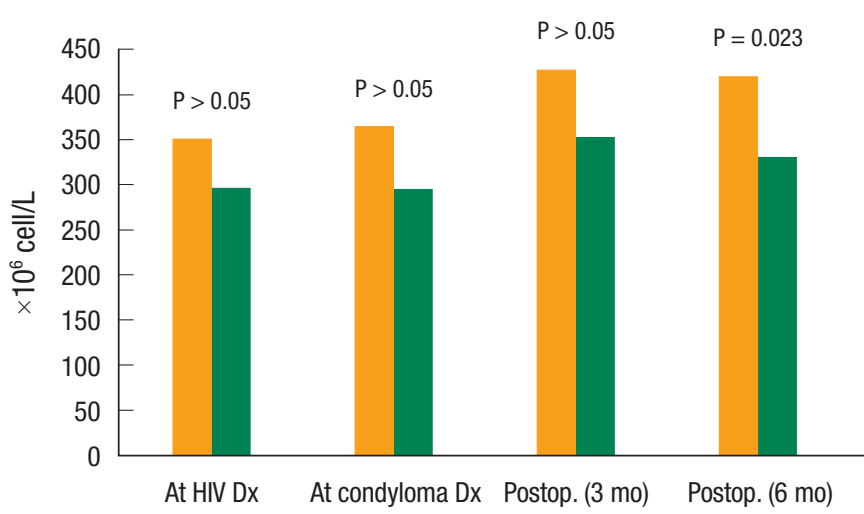

Fig. 1. Lower CD4 lymphocyte count was shown in recurrent patients than in nonrecurent patients at postoperative 6 months. HIV, human immunodeficiency virus; $\mathrm{Dx}$, diagnosis; Postop., postoperative. 


\section{Coloproctology ji Hyun sung, et al.}

Table 2. Risk factor analysis of recurrent condylomata

\begin{tabular}{|c|c|c|c|}
\hline & Nonrecurrent $(n=60)$ & Recurrent $(n=25)$ & P-value \\
\hline Age (yr) & & & 0.064 \\
\hline$<30$ & $22(36.7)$ & $8(32.0)$ & \\
\hline $30-39$ & $18(30.0)$ & $15(60.0)$ & \\
\hline $40-49$ & $14(23.3)$ & $2(8.0)$ & \\
\hline$\geq 50$ & $6(10.0)$ & $0(0)$ & \\
\hline HAART & & & 0.700 \\
\hline Therapy & $31(51.7)$ & $14(56.0)$ & \\
\hline None & $29(48.3)$ & $11(44.0)$ & \\
\hline \multicolumn{4}{|l|}{ Coinfections, n/answers (\%) } \\
\hline CMV & $37 / 57(61.7)$ & $21 / 25(84.0)$ & 0.082 \\
\hline HAV & $15 / 58(25.0)$ & $12 / 25(48.0)$ & 0.050 \\
\hline Syphilis & $21 / 59(35.0)$ & 2/25 (8.0) & 0.010 \\
\hline HBV & $4 / 60(6.7)$ & $4 / 25(16.0)$ & 0.189 \\
\hline \multicolumn{4}{|c|}{ CD4 lymphocyte counts (cells $/ \mathrm{mm}^{3}$ ) } \\
\hline At HIV diagnosis & $350 \pm 175$ & $294 \pm 139$ & 0.386 \\
\hline At condyloma diagnosis & $364 \pm 177$ & $293 \pm 121$ & 0.088 \\
\hline Postoperative (3 mo) & $426 \pm 163$ & $351 \pm 149$ & 0.058 \\
\hline Postoperative (6 mo) & $419 \pm 176$ & $329 \pm 137$ & 0.023 \\
\hline \multicolumn{4}{|c|}{ CD8 lymphocyte counts (cells/mm³) } \\
\hline At HIV diagnosis & $823 \pm 369$ & $834 \pm 254$ & 0.877 \\
\hline At condyloma diagnosis & $868 \pm 449$ & $866 \pm 417$ & 0.676 \\
\hline Postoperative (3 mo) & $1,013 \pm 546$ & $1,012 \pm 704$ & 0.486 \\
\hline Postoperative (6 mo) & $896 \pm 387$ & $838 \pm 373$ & 0.650 \\
\hline \multicolumn{4}{|l|}{ HIV RNA copies (copies/mL) } \\
\hline At HIV diagnosis & $51,283 \pm 170,533$ & $36,695 \pm 114,547$ & 0.287 \\
\hline At condyloma diagnosis & $40,530 \pm 152,106$ & $28,497 \pm 103,579$ & 0.355 \\
\hline Postoperative (3 mo) & $7,392 \pm 20,546$ & $3,393 \pm 13,130$ & 0.513 \\
\hline Postoperative (6 mo) & $10,250 \pm 32,062$ & $3,391 \pm 11,401$ & 0.574 \\
\hline
\end{tabular}

Values are presented as number (\%) or mean \pm standard deviation unless otherwise indicated.

HAART, highly active antiretroviral therapy; CMV, cytomegalovirus; HAV, hepatitis A virus; HBV, hepatitis B virus; HIV, human immunodeficiency virus.

three recurrences. Although $52.9 \%$ of the patients received antiretroviral drug treatment, no significant differences were observed between the recurrent and the nonrecurrent groups. The coinfection rates of cytomegalovirus, hepatitis A and hepatitis B virus associated with HPV infection were higher in the recurrent group compare to the nonrecurrent group. The infection rates of syphilis were higher in nonrecurrent group $(\mathrm{P}=0.010)$ (Table 2). During the study period, similar CD8 lymphocyte numbers were observed between the two groups. On the other hand, CD4 lymphocyte numbers were low in the recurrent group throughout the study period. CD4 lymphocyte numbers in the sixth postoperative month, in particular, were identified to be statistically significant $(\mathrm{P}=0.023)$ (Fig. 1). HIV RNA copy numbers exhibited no significant difference between the two groups.

\section{DISCUSSION}

Anal condyloma is a sexually-transmitted disease caused by the HPV. Even though it can be transmitted to any susceptible individual, it is more prevalent in HIV-positive patients. An anal condyloma is the most commonly reported anal disease in HIV-positive patients, and the occurrence of an anal condyloma is closely related to the HIV-positive patients' immune deficiency, sexual intercourse patterns, and number of sexual partners. This research addressed the commonly-involved immune deficiencies in HIV-positive patients. The study population was all male patients who had mostly 
contracted HIV infection through sexual contact. Among those, 60 out of the 85 patients (70.6\%) indicated that they were homosexuals, and a considerable number of nonrespondents were assumed to be homosexuals. Although a direct investigation was not conducted, HPV infection was thought to have been transmitted through anal sexual intercourse. According to Hwang et al. [11], greater numbers of male patients were prone to anal diseases in HIV-infected patients than in those without HIV infection. Moreover, homosexual intercourse was reported to be significantly higher in terms of transmission routes.

An anal condyloma reportedly has a recurrence rate of 20 to $50 \%$, and surgical treatment is generally known to have low recurrence rates. However, depending on the particular study, the values vary $[1,2]$. The postoperative recurrence rate was about $30 \%$ in this study. About $20 \%$ of the $30 \%$ with recurrence were intractable anal condyloma patients showing repeated recurrences after surgical treatment. Factors involved in the recurrence are anticipated to be reinfection from repeated sexual contact, postoperativelyremaining lesions, and reappearance of lesions caused by latent viruses in the body.

An anal condyloma is a disease spread through direct sexual contact. Hence, the incidence and recurrence rates have been reported highly in individuals with frequent sexual contacts and multiple sexual partners $[4,5,10]$. Thus, a considerable number of patients with recurrence have the possibility of reinfections. Although reinfections were thought to be included in this study, 1l, the possibility of reinfections was not recorded in the interviews with recurrent patients. In terms of the technical aspects of surgery, a single specialized surgeon performed all operations, and no differences were shown in the recurrence rates over time. Thus, this was considered an insignificant factor.

Cell-mediated immunity is associated with the reappearance of asymptomatic and latent infections. Previous studies have already verified the fact that cellular immunity is involved in HPV-induced lesions and have reported that anal-condyloma prevalence is more common in HIV-positive patients and transplant recipients managed with immunosuppressants [9, 12-15].

HPV generates the transformation of Langerhans cells, which play an essential role in the local cutaneous immune response, and sustains infections by consuming CD4 cells, CD16 (macrophages/natural killer cells) cells, and CD1a (Langerhans cells) cells in infected sites. These local responses are profoundly related to a weakened immune system of the whole body [9]. Le Poole et al. [6] presented evidences of immunosuppression, including decreases in transporters associated with antibody expression and dendritic cells, increases in interleukin-10 production by analyzing immunological indicators in anal condyloma lesion patients without HIV infections or other immunosuppressive treatment.

In this study, we planned the research by taking into account the possibility that different factors affecting the immunity of HIVinfected patients might influence the recurrence of an anal condyloma. However, CD8 lymphocytes, HIV RNA copies, antiretrovi- ral treatment, and other variables were not related with recurrence; however, the number of $\mathrm{CD} 4$ lymphocytes was found to be lower in the recurrent group than in the non-recurrent group. Because CD4 lymphocytes are excellent indicators reflecting the immunity condition of HIV-infected patients, the condition of the immune system of a patient should be associated with the recurrence of disease. However, statistically significant differences were shown only after the sixth postoperative month and did not completely coincide with the recurrent times of the patients.

A high prevalence of syphilis was exhibited in the nonrecurrent group. This was attributable to the inclusion of positive responders in qualitative test and did not reflect current infections. Critchlow et al. [16] reported that compared to non-HIV-infected patients, HIV-infected patients rarely shifted from positive to negative responses after HPV infections. The outcome was thought to be attributable to diminished responses generated by concurrent infections with various HPV subtypes or usual treatments. Moreover, a domestic study [17] reported that high-risk and multiple HPV infections were more frequently detected in HIV-infected patients than in patients without HIV infection. Thus, further study on the relationship between HPV subtypes and recurrence is thought to be essential. In addition, Mistrangelo et al. [7] reported that recurrence rates declined in the group administered with plants known to enhance the postoperative immunity of patients who had undergone anal condyloma surgery. In this regard, further studies on the application of immune-regulating substances pre- and postoperatively are expected to produce favorable results.

In conclusion, a marked decrease in CD4 lymphocytes was observed in the recurrent group compared to the nonrecurrent group with respect to anal condylomata in HIV-positive patients. Thus, diminished immunity mediated by CD4-related cells is thought to affect the recurrence of an anal condyloma.

\section{CONFLICT OF INTEREST}

No potential conflict of interest relevant to this article was reported.

\section{REFERENCES}

1. Breese PL, Judson FN, Penley KA, Douglas JM Jr. Anal human papillomavirus infection among homosexual and bisexual men: prevalence of type-specific infection and association with human immunodeficiency virus. Sex Transm Dis 1995;22:7-14.

2. Kodner CM, Nasraty S. Management of genital warts. Am Fam Physician 2004;70:2335-42.

3. Manzione CR, Nadal SR, Calore EE. Postoperative follow-up of anal condylomata acuminata in HIV-positive patients. Dis Colon Rectum 2003;46:1358-65.

4. Van Den Eeden SK, Habel LA, Sherman KJ, McKnight B, Stergachis A, Daling JR. Risk factors for incident and recurrent condylomata acuminata among men. A population-based study. Sex Transm Dis 1998;25:278-84. 
5. Habel LA, Van Den Eeden SK, Sherman KJ, McKnight B, Stergachis A, Daling JR. Risk factors for incident and recurrent condylomata acuminata among women. A population-based study. Sex Transm Dis 1998;25:285-92.

6. Le Poole C, Denman CJ, Arbiser JL. Immunosuppression may be present within condyloma acuminata. J Am Acad Dermatol 2008; 59:967-74.

7. Mistrangelo M, Cornaglia S, Pizzio M, Rimonda R, Gavello G, Dal Conte I, et al. Immunostimulation to reduce recurrence after surgery for anal condyloma acuminata: a prospective randomized controlled trial. Colorectal Dis 2010;12:799-803.

8. De Panfilis G, Melzani G, Mori G, Ghidini A, Graifemberghi S. Relapses after treatment of external genital warts are more frequent in HIV-positive patients than in HIV-negative controls. Sex Transm Dis 2002;29:121-5.

9. de la Fuente SG, Ludwig KA, Mantyh CR. Preoperative immune status determines anal condyloma recurrence after surgical excision. Dis Colon Rectum 2003;46:367-73.

10. Lee IS. Historical changes and the present situation of sexually transmitted diseases. J Korean Med Assoc 2008;51:868-74.

11. Hwang DY, Lee JS, Yoon SG, Rhyou JH, Song SG, Lee JK. Benign anal diseases on patients with HIV disease. J Korean Soc Coloproctol 2003;19:1-5.
12. Beutner KR, Tyring S. Human papillomavirus and human disease. Am J Med 1997;102(5A):9-15.

13. Gaspari AA, Zalka AD, Payne D, Menegus M, Bunce LA, Abboud $\mathrm{CN}$, et al. Successful treatment of a generalized human papillomavirus infection with granulocyte-macrophage colony-stimulating factor and interferon gamma immunotherapy in a patient with a primary immunodeficiency and cyclic neutropenia. Arch Dermatol 1997;133:491-6.

14. Sanclemente G, Herrera S, Tyring SK, Rady PL, Zuleta JJ, Correa LA, et al. Human papillomavirus (HPV) viral load and HPV type in the clinical outcome of HIV-positive patients treated with imiquimod for anogenital warts and anal intraepithelial neoplasia. J Eur Acad Dermatol Venereol 2007;21:1054-60.

15. Schell BJ, Rosen T, Rady P, Arany I, Tschen JA, Mack MF, et al. Verrucous carcinoma of the foot associated with human papillomavirus type 16. J Am Acad Dermatol 2001;45:49-55.

16. Critchlow CW, Hawes SE, Kuypers JM, Goldbaum GM, Holmes KK, Surawicz CM, et al. Effect of HIV infection on the natural history of anal human papillomavirus infection. AIDS 1998;12: 1177-84.

17. Moon SB, Moon SH, Park KJ. Detection and typing of human papillomavirus in anal condyloma acuminatum of HIV-positive patients. J Korean Surg Soc 2010;78:111-5. 